\title{
Digital Transformation of City Logistics Infrastructure
}

\author{
Bukrinskaya E.M. \\ Dep. of SCLM \\ SPbSEU \\ St. Petersburg, \\ Russian Federation \\ bukrin@ rambler.ru
}

\author{
Dyukova O.M \\ Dep. of SCLM \\ SPbSEU \\ St. Petersburg, \\ Russian Federation \\ olga_dukova@list.ru
}

\begin{abstract}
The paper covers the main provisions of the processes for transformation of cities logistics infrastructure through the analysis of publication activities of scientists in the field of city logistics and analysis of changes in the relation to the cities logistics infrastructure by the interested participants of urban systems. The possibilities of interests congruence with the help of digital tools are considered.
\end{abstract}

Key words: city-logistics, logistics infrastructure, "smart city", digital city technologies.

\section{INTRODUCTION}

Modern research in the field of city-logistics and urban infrastructure mainly comes down to solving particular problems of optimizing the transport systems. The reason is that the transport system is really a key factor for effective existence of the city, but it is not enough to increase the investment attractiveness of the urban economy. In addition, this is not the only requirement for the comfort of residence on the part of the creative class, which is the driver of urban economics growth. Despite the fact that recently quite a lot of interest has arisen in the implementation of advanced digital technologies in cities, issues regarding the formation of the remaining equally important subsystems remain unresolved. Partial digitalization will not bring the necessary emergent effect, and the absence of important elements of the logistics infrastructure of cities in the total integrated system, such as the public utilities system, engineering infrastructure, etc., can reduce the city attractiveness.

The purpose of the study: to analyze the reasons for underperformance of the digital transformation of the logistics infrastructure of cities and offer the tools to improve its performance.

Part 2 covers the analysis of the publication interest in the city-logistics in the global and Russian scientific community. Part 3 is devoted to the evolution of the concept and content of the logistics infrastructure of cities. Specification of the logistics infrastructure elements is proposed and the need for such an approach is justified. Part 4 covers the "smart city" technology, its advantages and disadvantages, as well as the experience of its implementation in various cities. Part 5 covers the tools of logistics infrastructure digitalization, in particular, an example of using the "digital twin" of the city.
Methods: the following methods of event analysis, synthesis of data obtained and application of analogies to existing objects were used in the study.

\section{CITY LOGISTICS}

In 2014 , the world urban population reached 3.9 billion people; in 2050 there will be 6.3 billion citizens. According to the UN data, it is expected that $70 \%$ of the world population will be urban citizens by 2050 .

Thus, it can be argued that the XXI century will be the era of big cities, metropolises and agglomerations. If 30 years ago only New York, Tokyo and Mexico City were considered world megacities, then in 2015, there are already 21 global metropolises, and according to UN forecasts, there will be about 30 by 2025 . The main problem for such entities is the synchronization of strategies for development and territorial planning of the city and suburbs (the most metropolises find a way to cope with this challenge without resorting to expanding administrative boundaries, simply coordinating development plans for the city and neighboring territories. However, the Russian legislation has no such tools. Therefore, it was necessary to take innovative decisions in order to relieve the center of Moscow, to bring a part of managerial and business functions to new territories) [15].

The developing countries make a significant contribution to the growth in a number of cities seeking to enter the world stage.

Firstly, it is due to the demographic potential, which is an indicator of passing the industrial stage in cities development. European countries have passed it a long time ago, now they are finishing the post-industrial stage associated with the development of high-level services (financial, insurance), while mass services are transferring to developing countries now.

Today about $45 \%$ of the world population lives in China, India, Brazil, Russia, Mexico, Indonesia and Turkey. And although these countries (they are sometimes called E7 countries) are inferior in terms of socio-economic development to the G7, their role in the world economy will grow significantly in the coming decades. The projected growth rates of these countries in the period through to 2025 will be $5-6 \%$, in contrast to $2-3 \%$ of the OECD countries [15].

Such trends confirm the need to study the ways to manage cities development processes. 
The greatest interest is studies in the field of city logistics. According to the research [7], the rapid growth of scientific publications regarding the city logistics confirms the viability and relevance of this concept.

The publication activities of foreign scientists have shown increase in a number of scientific articles from 2010 to 2016 by more than 5 times. Definitions and terminology [1, 4, 6 , 8], methods and models used to optimize the cities logistics system $[4,6,10,12]$ are among the main issues arising in the publications, and innovative solutions $[5,11]$, the policy of local authorities and sustainable development are followed in much smaller numbers. This confirms that methodological aspects are still fundamental for the scientific community. These indicators are characteristic both for developed countries (mainly European) and for developing ones.

It is worth noting that another similar study [13] covering the horizon from 1993 to 2018 shows that the main problems in the articles relate to the optimization of transport systems in cities, particularly to the goods transportation [2, 3, 9].

Thus, the interest of foreign researchers mainly comes down to the management and optimization of transport and goods flows within the framework of the urban economy. It is worth noting that these processes are indeed fundamental in the construction of the city's logistics system. However, the authors also note significant difficulties in the design of such systems in cities. This is due to some difficulties, among which there are:

1. The need to coordinate the interests of a large number of participants (suppliers, carriers, vendors, buyers, city authorities and businesses).

2. Lack of information support to for make decisions. It should be noted that the issue is a lack of even basic statistical information.

In our opinion, the above difficulties are correlated with each other and can be resolved in its entirety.

Domestic researchers also note the importance of solving more insistent issues related to transport and goods flow in city logistics [21, 23]. Recently, however, significant interest in the waste logistics should be noted [15]. This interest is firstly associated with a request from the state and municipal government in connection with the waste treatment system formation in Russia.

In most cases, Russian scientists, while defining the term of city logistics, adhere to the process approach. That is, they determine the scope of activities within the framework of logistics processes management within the territory of urban locality.

A common trend for scientists around the world involved in the city logistics is the interest from the governing bodies of large cities. Medium and small cities are underfunded around the world, so implementation of innovative and logistics approach at such a level of relationship complexity will be innovative by default, can be considered by them only for the long term. However, it should be noted that they use partial optimization in some areas, for example, in building the transport infrastructure quite successfully.

\section{THE CONCEPT OF CITY LOGISTICS INFRASTRUCTURE}

The logistic infrastructure according to D. Bowersox includes a set of subsystems that ensure functioning of supply chains in the territorial economic system by optimizing material and associated flows [14]. On detailing this definition, V. I. Sergeev notes that the logistics infrastructure includes a number of subsystems including the transport network; transport fleet; logistics service facilities; transportcargo hubs; information channels and systems; system of unified cargo units; financial support system for logistics processes; regulatory system to ensure logistics activities; participants in logistics processes [19].

As a result of the analysis of term "logistics infrastructure" interpretations, various publications highlighted the existence of two interconnected approaches to interpretation of the term: logistics infrastructure as a set of objects and logistics infrastructure as a set of processes $[14,17,19,20,22,23]$. The studies in the field of city logistics infrastructure have particular relevance in the logistics infrastructure development. Cities become drivers of the growth for the economies of entire countries and, in fact, they are the innovation grounds.

No matter how the size and population of cities grow, it is important to constantly work to maintain and increase the comfort and quality of the urban environment. This fact becomes the basis for implementation of all new projects and renovation of old urban areas.

Russian cities are subject to significant pressure from the Soviet heritage in terms of architecture and infrastructure.

Unfortunately, a noticeable change in approaches can be observed only in the largest cities (Moscow and Saint Petersburg), but the practice is slowly but surely relating to other cities.

The main problem, in our opinion, is the absence of a mechanism for stakeholders' coordination. This aspect leads to the impossibility of developing a single urban development plan, the absence of strategic indicators, for which any city in the country should seek, regardless of its size. In this regard, now there is a set of infrastructure projects that are of great importance, but do not take into account the cumulative negative effect of their joint implementation. This factor causes significant social strain among the population. Moreover, this effect occurs not only in large million cities (a project for church construction instead of a park in Yekaterinburg), but also in small cities (a project for landfill construction at Shies station in the Arkhangelsk Region).

By analogy with the countries competitiveness rating (IMD) calculated by the International Institute for Management Development in Geneva, four groups of factors can be distinguished which should be taken into account when assessing the integral indicator of the city competitiveness level:

- economy state;

- effectiveness of city management,

- business performance,

- infrastructure state.

Therefore, the infrastructure state is one of the factors of both investment attractiveness and city competitiveness. In this case, the infrastructure state affects the rate and nature of city economic development, and the efficiency of business activities.

Conventionally, the components of city logistics infrastructure include: 
- production and business infrastructure (vehicles, communications, energy and utilities);

- transport infrastructure (roads, stations, ports, terminals, warehouses, etc.);

- organizational and institutional infrastructure (trading, legal, audit, consulting firms, advertising agencies, business incubators, business centers, technology parks, etc.);

- social infrastructure (educational, health, cultural, recreational and sports institutions);

- financial infrastructure (banks, insurance and investment companies, pension funds, etc.);

- information infrastructure (information networks; communication systems, telecommunications, help systems, etc.).

However, in our opinion, it is necessary to separate house building and the infrastructure of urban areas improvement as a separate component.

One of the main problems in house building is that the various components of a single urban logistics infrastructure are created by different entities at different times, which leads to the chaotic city development, unjustified expectations from users and problems of the objects quality. If we consider the city infrastructure as a macro level (Fig.), then we can note that now its development is going from bottom to top, i.e. at the first stage, the infrastructure of individual quarters is created (a contract is concluded between developers and municipal authorities on the integrated development of the territory, which provides for creation of all infrastructure types on a separate area to be developed), then these quarters are combined, first of all, with transport infrastructure to the districts; at the third stage, the infrastructure of individual districts fits into the unified city infrastructure.

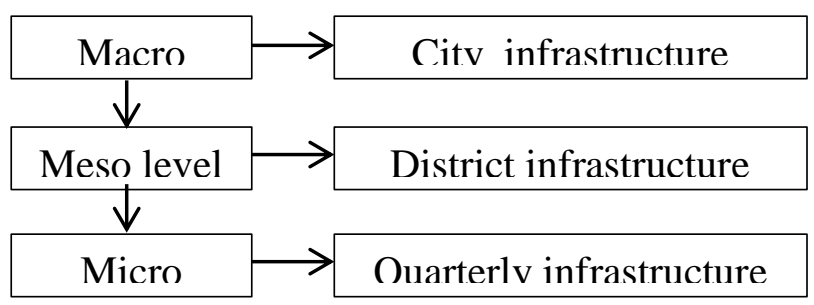

Fig. 1. Levels of logistics infrastructure within the framework of the city [18]

At the legislative level, various urban development strategies are called upon to solve this problem. Thus, the Strategy of social and economic development of Saint Petersburg for the period through to 2035 adopted on June 26, 2018 , one of the tasks is to implement the optimal model of spatial development, which is intended to accommodate the population, provide for social, transport, utilities infrastructure, public amenities and public spaces for the effective development of the economy and social sector.

However, in practice, the key subject that creates the infrastructure objects is still the builder or developer that, on the one hand, seeks to create marketable product, and on the

The approach belongs to Gabriel Lanfranchi, a director of urban programs, CIPPEC, Buenos Aires, a founder of the MetroLab program at the Massachusetts Institute of Technology (MIT), and a member of the special other hand, bears social responsibility for creating the certain quality level of city population living.

Thus, a critical situation is observed in the housing development market of Russian cities. The strategies developed by the city governments (macro level) do not take into account the interests of the business community (micro level). In addition, the external environment (legislation) introduces new, more stringent restrictions to the activities in this industry. All these trends lead to decreasing a number of players in the market and slowdown in rates of new housing, which will certainly reduce the competition level.

The urban redevelopment infrastructure, to which we refer the creation of pedestrian streets, boulevards, squares, that is, that is now commonly called public spaces, will belong to the level of mesologistic urban infrastructure. A greater level of system complexity requires the coordination of even more stakeholders. This issue can be resolved by digitalizing the city infrastructure. In this aspect, we can talk about a certain stage in the smart evolution of development: from a smart home and smart quarter to a smart city that will meet the customer expectations to the maximum.

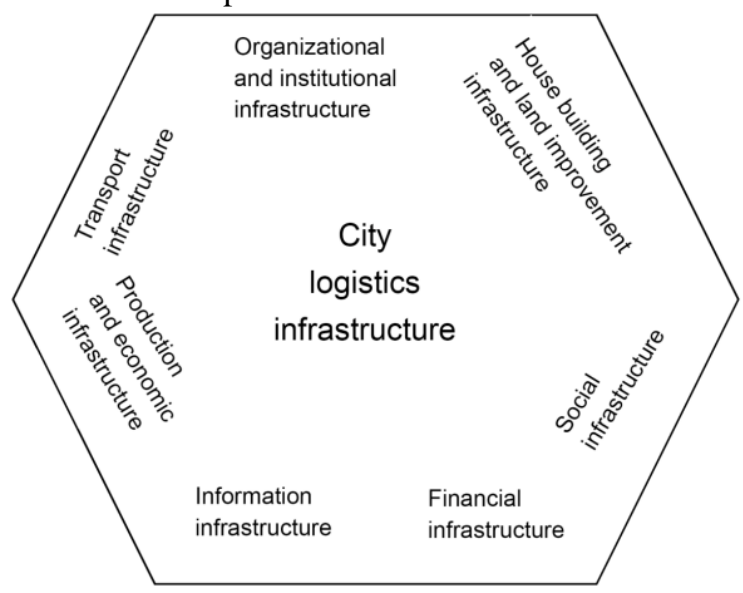

Fig. 2. Elements of the city logistics infrastructure

Modern city planning science uses the approach that allows tracing the infrastructure evolution in terms of responding to requests from city residents, since they are the main element affecting and being affected during the effective system building.

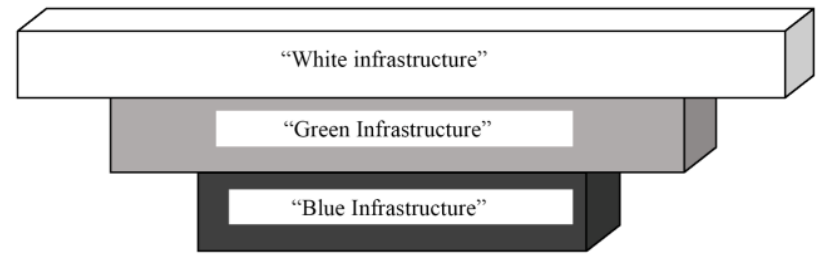

Fig. 3. Urban infrastructure evolution ${ }^{1}$

At the first stage of cities development, which began during the first industrial revolution, the "blue infrastructure" appeared - sanitary and hygienic water supply lines, sewage and waste treatment system. At the second stage (the second half of the 20th century) the "green infrastructure" appeared

department of urban studies and regional studies at the MIT. Source: Overchenko M. Gabriel Lanfranchi: cities becomes the inequality symbols. // Vedomosti dated 06.08.2018 
- parks, squares, development of biodiversity systems. Today, the "white infrastructure" is developing rapidly - these are the facilities allowing the city to become dynamically developing, this is the layer allowing "smart city" system implementation. Moreover, it should be noted that the omissions that appeared at the first levels require significant investment to correct at the higher level. And in some cases, the question is the impossibility of moving to the third level.

However, the studies currently being carried out show that the development of various component sections of the urban infrastructure is uneven, i.e., the entire urban infrastructure system exists simultaneously at all three stages of evolution. This greatly complicates the development, implementation and management of infrastructure projects in cities (for example, implementation of Smart City tools in urban life safety systems cannot be coupled to the waste treatment system until the latter is simply formed).

\section{THE "SMART" CITY CONCEPT}

To solve the problem of managing the urban system, which internal communications are becoming more complicated at a rapid rate, the Smart City concept was invented.

Today, there is no adequate definition for the Smart City term. In general, this is a system where the existing resources of city services are used in the best way and ensure maximum safety of city life. For this purpose, it is necessary to organize close communication between individual projects of the "smart city" (video surveillance, public services, intelligent transport and other systems) on a scale of the city or region [16].

It is incorrectly to consider the smart city also known as the "intelligent city" and "digital city" only as an area saturated with technologies. In this case, the technologies are more likely to be a means for achieving a universal goal generation of a comfortable urban environment as a system. And the emergent property of this system will be primarily the site arrangement for dialogue with the local population and the generation of joint future in accordance with their aspirations, as well as the mode of actions. That is, the "smart city" is a city that uses high technologies for communication to provide fruitful use of available resources to improve living standards, less damage to the environment, support the innovations implementation, as well as to rationalize energy use and save costs. Thus, we can conclude that the "smart city" concept acts as an integral component of the cyclical economic system.

The smart city must have a qualified managerial and analytical resource in order to forecast probable negative trends as exactly as possible. To eliminate the imperfections of modern cities, new IT systems are produced and tested, which use the Big Data analytics (citizens data assets), integrated computer simulation, and use the results of the latest scientific research in the field of sociology and human behavior. Therefore, it is important to take into account a variety of approaches in smart city projects - from research of human behavior to management of resources and infrastructure. Fundamentally, this is a network of interrelated mechanisms, and information and communication technologies make it possible to visualize their interaction, manage current flows that involve not only city structures of different levels, but also the suburbs, and in some cases, even other cities. From the point of view of information and computer technologies, general optimization in various fields, balance of material resources, which include levels from the city budget to food and waste, as well as intangible ones - urban population, energy and information are important. As it can be seen, the logistics concept fully meets the modernity requirements.

\section{DIGITALIZATION PROCESSES IN THE CITY LOGISTICS INFRASTRUCTURE}

Advantages of digital technologies are used in the logistics of the city at all stages. The main trends include the use of 3D printing, Big Data, self-propelled vehicles, unmanned aerial vehicles $[5,11]$. These technologies are used both in isolation and in combination.

The creation of digital twins is one of the examples for using the digital technologies to solve urban problems. Today, in Russia we can talk about one project - the "Kronstadt Digital Twin". Kronstadt is part of Saint Petersburg and, in principle, is considered as a site for the experience extension to all the city districts.

It should be noted that in March 2019, the Smart City technology standard was approved in Russia, one of the components of which was "digital twins".

The pilot project was presented at the Saint Petersburg International Economic Forum (SPIEF) in 2019. The developers (the Megafon was a developer) had the main tasks:

- identification of urban land improper use;

- identification of objects built without permission;

- assessment of the prospects for emergence of new objects in the area of historical urban development.

The "digital twin" creation tool allows simulating various situations based on the existing conditions, transferred to 3D format. As practice has shown, the model has a great future not only in solving the assigned tasks, but also in the role of a source for obtaining and providing the necessary information for all participants in the experiment. The developers emphasize that the tool is able to act as an integrating site to resolve the conflict of interests of various participants in the city logistics system.

There are about 30 examples for building "digital twins" of cities in the world. And each city has its own implementation priorities.

For the Singapore "twin" the main task was to simulate the construction of new buildings, taking into account blacking out the existing ones. Then it became possible to connect pedestrian and passenger traffic data, data on a rate of particular area safety to this system.

In India, they use this tool to build new cities in an effort to optimize the cost of creating engineering infrastructure. However, this country has become a strong example of the negative result from investments in the digital technologies development. For India, such a project has become vitally necessary because the country population will exceed the population of China by 2022 according to some estimates. Financing of projects of about $\$ 7.5$ billion generally provided for private investments, and that, in our opinion, 
could not ensure their effective implementation. It is due to the private business cannot provide for an independent site for ensuring the interests of all participants. As a result, the real cities built using digital technologies are being destroyed due to insufficient attention to development of production and engineering infrastructure, and environmental consequences. All these issues could be resolved at the design stage of the city, if the "digital twin" functionality were saturated with data from related departments and used in full.

\section{CONCLUSIONS}

The economy digitalization is not a cure-all solution for all its "diseases". The systemic violations will not be resolved if they are converted to digital format. The digital transformation of urban infrastructure shall begin from the lower levels - micro-logical, but this process shall fully comply with the chosen city development strategy - macrological solutions.

\section{REFERENCES}

[1] Alho, A., Silva, J. D. A., de Sousa, J. P. (2014). A state-of-the-art modeling framework to improve congestion by changing the configuration/enforcement of urban logistics loading/unloading bays. Procedia-Social and Behavioral Sciences, 111, 360-369.

[2] Comi, A., Delle Site, P., Filippi, F., Nuzzolo, A. (2012). Urban freigh transport demand modeling: A state of the art. European Transport \Trasporti Europei, Issue 51, Paper N ${ }^{\circ}$ 7, ISSN 1825-3997.

[3] Evrard Samuel, K., Cung, V.D. (2015). Towards evaluation tools for last mile delivery projects: insights from France, 6th METRANS International Urban Freight Conference, Long Beach CA, USA, October 21-23.

[4] Jiang, Z. H., \& Liu, J. (2016). Development of Urban Logistics in China. In Contemporary Logistics in China (pp. 179-191). Springer Berlin Heidelberg.

[5] Kunze, O. Replicators, Ground Drones and Crowd Logistics A Vision of Urban Logistics in the Year 2030 Article (PDF Available) in Transportation Research Procedia 19:286-299 December 2016

[6] Nuzzolo, A., Comi, A. (2014). City logistics planning: demand modeling requirements for direct effect forecasting. Procedia-Social and Behavioral Sciences, 125, 239-250.

[7] Parisa Dolati Neghabadi, Karine Evrard Samuel, Marie-Laure Espinouse. City logistics : a review and research framework. RIRL 2016 EPFL, Sep 2016, Lausanne, Switzerland. hal-01420815

[8] Russo, F. and Comi, A. (2018). From city logistics theories to city logistics planning. City Logistics 3 - towards sustainability and liveable cities, Taniguchi E. and Thompson, R.G. (eds), ISTE Ltd, John Wiley and sons, Londom, UK, pp. 329-348. ISBN: 978-1-78630-207-6

[9] Russo, F., Comi, A. (2012). City characteristics and urban goods movements: A way to environmental transportation system in a sustainable city. Procedia-Social and Behavioral Sciences, 39, 61-73.

[10] Taniguchi, E., Thompson, R. G., Yamada, T. (1999). Modelling city logistics. In City Logistics, Research, Kyoto,

[11] Taniguchi, E., Thompson, R. G., Yamada, T. (2014). Recent trends and innovations in modelling city logistics. Procedia-Social and Behavioral Sciences, 125, 4-14.

[12] Taniguchi, E., Thompson, R.G., Yamada, T. (2012). Emerging techniques for enhancing the practical application of city logistics models. Procedia-Social and Behavioral Sciences, 39, 3-18.

[13] Wanjie Hu , Jianjun Dong, Bon-gang Hwang, Rui Ren, Zhilong Chen A Scientometrics Review on City Logistics Literature: Research Trends, Advanced Theory and Practice, Sustainability 2019, 11, 2724.

[14] Bowersox D. J. Logistics: integrated supply chain/D. J. Bowersox D. J. Klos; translated from English by N. N. Baryshnikova, B.S. Pinsker. M.: : Olimp-Business, 2005. - p. 640

[15]Bukrinskaya E.M. City logistics: training aids. /E.M. Bukrinskaya. $\mathrm{SPb}$ : Publishing House SPbSEU, 2015. - p. 83

[16]Bukrinskaya E.M. Digitalization of the city logistics management system// Bulletin of the Management Faculty, SPbSEU. - Pumblishing House: SPbGEU. - 2019 (under editing).
17] Gadzhinsky A.M. Logistics: textbook / A.M. Gadzhinsky. - 2nd edition, - M.: : Marketing, 1999. - p. 228

[18]Dyukova O.M., Loktionova E.V. Housing development logistics infrastructure: modern understanding and trends// Russian economic webzine. - 2019. - No. 1

[19]Corporate logistics. 300 answers to professionals' questions /edited by V.I. Sergeyev. - M.: Infra-M, 2005. - p. 976

[20]Nerush Yu. M. Logistics: textbook /Yu. M. Nerush. - 4th edition, rev. and corr. - M. : TK Velbi; Publishing House, 2006. - p. 520

[21]Popov P.V., Miretsky I.Yu. Simulation of region logistics infrastructure: Monograph/ P.V. Popov, I.Yu. Miretsky. - Volgograd: Publishing House of the Volgograd Management Institute - RANEPA Branch, 2017. - p. 182

[22] Stok J. R. Strategic logistics management /J. R. Stok, D. M. Lambert; translated from the 4th English edition V.N. Egorova; edited by. V.I. Sergeyev. - M.: Infra-M, 2005. - p. 797

[23] Shvalov P.G. Fundamentals of the urban agglomeration logistics infrastructure management // Review of the Irkutsk State Economic Academy. - 2014. - No. 3. - pp. 37-45. 